\title{
Calculating expected deaths: a comparison of two methods
}

\author{
A C CHOVIL
}

From the Department of Preventive Medicine and Community Health, School of Medicine, University of South Carolina, Columbia, South Carolina 29208, USA

ABSTRACT A comparison is presented between the traditional "person-years" and more recently described "prospective model" methods for calculating mortality expectations. Problems arising from the fact that expectations under the person-years method are calculated on the basis that a null hypothesis is true, which results in artificial figures that, at least theoretically, are meaningless if the hypothesis is rejected, are discussed. Data are presented from two studies in which expectations have been calculated both ways, showing important differences between the two methods with an exaggeration of the expectation when the study group has an above normal mortality experience. It is suggested that the person-years methodology should be replaced by that of the prospective model.

The classic method of calculating expected deaths by a modified life table, customarily known as the "person-years method," is usually accepted without question although an alternative "prospective method" has been proposed. ${ }^{1}$ The present paper will discuss some problems with the person-years methodology and compare results obtained by it with those obtained by the prospective method.

The ideal experimental model for research studies, typified by Bradford Hill in 1953 in his classic Cutter Lecture at Harvard, ${ }^{2}$ involves the forward observation and comparison of matched study and control groups. This is the preferred design used in random clinical trials and other prospective studies. It is, however, seldom possible in occupational mortality studies. The historical prospective design, which is commonly used, largely fulfills the forward observation element, but there is rarely even an adequate control group, much less a matched one. Lacking such, it has become customary to compare mortality rates of subjects with those of some other population - often the national rates, using a modified life table approach, usually referred to as the person-years method, to estimate the number of deaths that would have been expected. Problems of determining a suitable comparison population have been discussed extensively elsewhere ${ }^{3}$ and will not be considered here.

\section{Problem}

The origins of the person-years technique extend back

Accepted 10 November 1986 to the early 1950 s, the pre-computer era, when feasibility of manual calculations was paramount in determining methodology. Theoretical problems with the method have been voiced intermittently over the years beginning with Berkson in $1958,{ }^{4}$ and subsequently by Miettinen, ${ }^{5} \mathrm{Hyde}^{6}{ }^{6}$ Mantel et $a{ }^{7}{ }^{7}$ and others. Alternative methods were suggested but were never translated into changes in practice. A belated algebraic justification of the person-years method was published in 1983 by Berry ${ }^{8}$ It seems, however, to be based on an assumption that the person-years expectation is about equal to that which might have been observed in an experimental model, an assumption which the present paper will suggest is not always true.

An important feature of the person-years method is that it is really a comparison of rates and not of actual numbers of deaths. It tests a null hypothesis that the mortality rate of the study group is the same as that of the control population and it does so without the use of a separate and truly independent control population. If the null hypothesis is true an expectation calculated by applying the control population's mortality rates to the study population's survival experience (the person-years method) will equal the observed mortality. This equality is susceptible to statistical testing. If there is no difference one fails to reject the null hypothesis and the expectation becomes uninteresting clinically. If one rejects the null hypothesis, however, the expectation becomes theoretically meaningless and should be discarded, as it was calculated on the basis that the hypothesis was true. One has created an expectation that is just a 
"straw man" for use in a comparative mathematical exercise. It has no reality and theoretically should have no further use. This seldom is the outcome, and the expected numbers of deaths generated in this way are customarily used to develop mortality ratios, attributable risks, etc. It then becomes important to determine if this use can introduce significant bias into studies.

Several authors seem to have described an essentially similar alternative method of calculating expected deaths that would not have these limitations and would more closely approximate to the experimental model. Most recently Hartz et al published it under the title "prospective model." 8 This work was the subject of criticism on the grounds that the method had less statistical power than person years. The essence of these alternate methods is to create a hypothetical, age matched, control group with the survival (mortality) experience of the reference population. This makes a control group that is truly independent of the study one and permits comparison of number of deaths, not just rates. For convenience, Hartz's name of prospective model will be used generically for these alternate methods.

The theoretical difference in outcomes of the two methods depends on the difference in their survival experience. That of the prospective model control group, which more nearly approximates the ideal experimental model, may be considered the "normal" pattern. If the study group has a higher than normal mortality (poorer survival) using this will result in a relative deficit of person-years of observation and an underestimate of expected deaths (with inflation of standard mortality ratios (SMRs)). The converse holds when the study group has a better than normal survival. This latter factor, which is common in occupational studies, due to the healthy worker effect, will deflate SMRs even more by inflating the number of expected deaths.

\section{Experimental data}

Data from two studies, for which expectations have been calculated both ways, are available. In the first Finkelstein et al reported expected deaths in four cohorts of workers with silicosis by the person-years method and also their actuarial survival probabilities. ${ }^{9}$ The latter really form the basis for the prospective model. .Finkelstein's data permit the calculation of the probability of dying (which is the equivalent of the expected number of deaths), both by the person-years and prospective methods, for each of the four subgroups of his study. The probability of dying may be calculated from these data either from the reported mortality experience or as the complement of the probability of survival, with slightly differing results. Both are given with resulting SMRso in table 1 . It will be noted that the person-years method results in consistently lower expectations and? higher SMRs. It is of interest that when the observecect: risk is calculated from the mortality data (A), the SMR falls below 100 for the two younger cohorts suggesting a possible healthy worker effect that woulc not be inconsistent with anecdotal accounts of these्d subjects, among whom an excess of deaths from? tuberculosis was limited to the older cohorts. के

A study of nickel sinter workers, who get excessiverespiratory cancer, also provides comparative data. ${ }^{10}$ Expectations were calculated both ways. Subjects inc that study were stratified by exposure to show the dose? response. These data (shown in table 1 for deaths from $\frac{\Phi}{3}$ all causes and in table 2 for lung cancer) confirm the exaggeration of expected deaths produced by the person-years method. The small numbers and round- $\overrightarrow{0}$ ing off in the calculations probably account for thei two cells in which the prospective figures are slightlye higher in table 3.

\section{Conclusions}

These data show that under some conditions the difference between the two methods is certainly more than trivial. This would seem to negate Berres'soo assumption of their being "approximately" equer. (however that imprecise concept should be defined within the exactitude of statistical terminology). It has been suggested that the prospective method wouldo yield rather meaningless data in prolonged studieso when most subjects are dead, as both observed and $\stackrel{\mathbb{Q}}{\mathscr{Q}}$ expected would approach $100 \%$. This is true, but if there were indeed differences in mortality patterns 3 they could easily be detected by observing any? difference in secular changes in rates. This could giver invaluable information when an exposure may accel-

Table 1 Probability of dying (up to 1979). ${ }^{9}$ (SMRs in parentheses)

\begin{tabular}{|c|c|c|c|c|c|}
\hline Cohorts & $1940-9$ & $1950-9$ & $1960-9$ & $1970-9$ & \\
\hline $\begin{array}{l}\text { Observed A } \\
\text { Observed B }\end{array}$ & $\begin{array}{l}0.93 \\
0.95\end{array}$ & $\begin{array}{l}0.80 \\
0.88\end{array}$ & $\begin{array}{l}0.46 \\
0.53\end{array}$ & $\begin{array}{l}0.13 \\
0.24\end{array}$ & $\frac{D}{0}$ \\
\hline $\begin{array}{l}\text { Expected } \\
\text { (Prospective model) } \\
\text { SMR A } \\
\text { SMR B }\end{array}$ & $\begin{array}{l}0 \cdot 81 \\
(115) \\
(117)\end{array}$ & $\begin{array}{l}0.72 \\
(111) \\
(122)\end{array}$ & $\begin{array}{r}0.48 \\
(96) \\
(110)\end{array}$ & $\begin{array}{r}0 \cdot 14 \\
(93) \\
(171)\end{array}$ & N \\
\hline $\begin{array}{l}\text { Expected } \\
\text { (Person-years) } \\
\text { SMR A } \\
\text { SMR B }\end{array}$ & $\begin{array}{l}0.42 \\
(221) \\
(226)\end{array}$ & $\begin{array}{l}0.52 \\
(154) \\
(169)\end{array}$ & $\begin{array}{l}0.37 \\
(124) \\
(143)\end{array}$ & $\begin{array}{l}0.08 \\
(162) \\
(300)\end{array}$ & $\underset{\frac{\sigma}{c}}{\frac{\sigma}{c}}$ \\
\hline \multicolumn{6}{|c|}{$\begin{array}{l}\text { Observed A calculated from actual deaths reported. } \\
\text { Observed B calculated from Finkelstein's table 5, "Cumulative } \\
\text { probability of survival." } 9\end{array}$} \\
\hline
\end{tabular}


Table 2 Deaths: lung cancer (nickel refiners $\left.{ }^{10}\right)($ SMRs in parentheses)

\begin{tabular}{|c|c|c|c|c|c|c|c|}
\hline Exposure cohort & $l$ & 2 & 3 & 4 & 5 & 6 & 7 \\
\hline Observed & 0 & 1 & 3 & 4 & 6 & 13 & 11 \\
\hline $\begin{array}{l}\text { Expected } \\
\text { (Prospective model) }\end{array}$ & $\begin{array}{l}0.47 \\
(-)\end{array}$ & $\begin{array}{l}0.36 \\
(277)\end{array}$ & $\begin{array}{l}0.54 \\
(555)\end{array}$ & $\begin{array}{l}0 \cdot 60 \\
(666)\end{array}$ & $\begin{array}{l}0.68 \\
(882)\end{array}$ & $\begin{array}{c}0 \cdot 76 \\
(1710)\end{array}$ & $\begin{array}{c}0 \cdot 84 \\
(1309)\end{array}$ \\
\hline $\begin{array}{l}\text { Expected } \\
\text { (Person-years) }\end{array}$ & $\begin{array}{l}0 \cdot 50 \\
(-)\end{array}$ & $\begin{array}{l}0.36 \\
(277)\end{array}$ & $\begin{array}{l}0.42 \\
(714)\end{array}$ & $\begin{array}{l}0.56 \\
(714)\end{array}$ & $\begin{array}{l}0.57 \\
(1052)\end{array}$ & $\begin{array}{c}0.65 \\
(2000)\end{array}$ & $\begin{array}{c}0.76 \\
(1447)\end{array}$ \\
\hline
\end{tabular}

Table 3 Deaths: all causes (nickel refiners ${ }^{1}$ )(SMRs in parentheses)

\begin{tabular}{|c|c|c|c|c|c|c|c|}
\hline Exposure cohorts & 1 & 2 & 3 & 4 & 5 & 6 & 7 \\
\hline Observed & 7 & 6 & 13 & 9 & 11 & 22 & 17 \\
\hline $\begin{array}{l}\text { Expected } \\
\text { (Prospective model) }\end{array}$ & $\begin{array}{l}6 \cdot 5 \\
(108)\end{array}$ & $\begin{array}{l}5 \cdot 4 \\
(111)\end{array}$ & $\begin{array}{c}7 \cdot 3 \\
(178)\end{array}$ & $\begin{array}{l}7 \cdot 8 \\
(115)\end{array}$ & $\begin{array}{c}8 \cdot 5 \\
(129)\end{array}$ & $\begin{array}{l}10 \cdot 1 \\
(218)\end{array}$ & $\begin{array}{l}10 \cdot 5 \\
(162)\end{array}$ \\
\hline $\begin{array}{l}\text { Expected } \\
\text { (Person-years) }\end{array}$ & $\begin{array}{l}6 \cdot 8 \\
(103)\end{array}$ & $\begin{array}{l}5 \cdot 5 \\
(109)\end{array}$ & $\begin{array}{c}6 \cdot 2 \\
(210)\end{array}$ & $\begin{array}{l}7 \cdot 7 \\
(117)\end{array}$ & $\begin{array}{c}7 \cdot 7 \\
(143)\end{array}$ & $\begin{array}{c}9 \cdot 4 \\
(234)\end{array}$ & $\begin{array}{c}9 \cdot 8 \\
(173)\end{array}$ \\
\hline
\end{tabular}

erate the development of a disease, without actually increasing the incidence, which is seldom available now.

The person-years method results in an underestimation of expected deaths when a study cohort has an excessive mortality. Possibly its use in cohorts with grossly increased mortality rates from one cause may result in apparent excess mortality from other conditions due to this overall reduction in the expectations. This could explain the apparent excess of gastrointestinal and laryngeal cancer in some studies of asbestos workers. This, however, is a matter of relatively small moment and may be easily checked. Of much greater concern is the possibility that the exaggeration of the expected numbers in cohorts with lower than normal mortality-a common occurrence due to the healthy worker effect-may help mask real increases of occupational importance. The use of the person-years method in these circumstances, despite its reputed greater power to detect differences in mortality rates, may thus actually tend to hinder those who are trying to identify occupational hazards. It is suggested that the time may have come to replace it with the prospective method in the interests of accuracy and reduction of bias.

\section{References}

1 Hill AB. Observation and experiment. $N$ Engl $J$ Med 1953;248:995-1001.

2 Medical Research Council Environmental Epidemiology Unit. Expected numbers in cohort studies. Southampton: MRC, 1984. (Scientific report No 6.)

3 Berkson J. Estimation of the internal rate in actuarial calculations: a critique of the person years concept. Journal of the American Statistical Association 1958;53:457-82.

4 Miettinen OS. Standardization of risk ratios. Am J Epidemiol 1977;96:383-8.

5 Hyde J. Testing survival under right censoring and left transaction. Biometrika 1977;64:225-30.

6 Mantel N, Bohidar N, Cimenera J. Mantel-Haenszel analysis of litter matched time-to-response data with modifications for recovery of interlitter information. Cancer Res 1977;37:3863-8.

7 Berry G. The analysis of mortality by the subject years method. Biometrics 1983;39:173-84.

8 Hartz AJ, Giefer EE, Hoffman RG. A comparison of two methods for calculating expected mortality. Statistics in Medicine 1983;2:381-6.

9 Finkelstein M, Kusiak R, Suranyi G. Mortality among miners receiving workman's compensation for silicosis in Ontario 1940-75. J Occup Med 1982;24:663-7.

10 Chovil A, Sutherland RB, Halliday M. Respiratory cancer in a cohort of nickel sinter plant workers. Br J Ind Med 1981;38:322-33. 